\title{
Birthday surprises
}

Now you are 16.

\section{Erika Cule}

Strains of Happy Birthday greeted me from the kitchen.

“... Happy Birthday dear Elizabeth, Happy Birthday to you!”

I grinned and embraced my father. "Many happy returns, love," he said. He ruffled my hair affectionately. "Sweet sixteen, quite something."

Grandma beckoned from her armchair. "Come and give your Nan a kiss."

I rushed to hug her. She tried to hide a wince as I brushed against her scars. "Your future should be in your inbox now," she said, with a nod towards my laptop. "I asked for it to be delivered this morning."

Thoughts of my father's gift forgotten, I snatched up my machine and made for our neighbourhood coffee shop. I needed some privacy while I studied what life had in store. Installed on a sofa with a coffee, I logged on. Among the dozens of birthday greetings was the message from sequencing@545.com.

\section{Subject: Your Complete Genome \\ Sequence \\ Birthday Greetings, Elizabeth.}

Thank you for ordering Your Complete Genome Sequence High-Quality Version from 545.com. Our Annotation Service supplies a detailed genotype analysis. We analysed more than 6 million single nucleotide polymorphisms, alongside mini- and micro-satellites, deletions, inversions and copy number variations. We report known phenotypic associations, together with significance levels. All associations reference peer-reviewed publications and are cross-referenced to GenBank and Online Mendelian Inheritance in Man where relevant.Your annotated sequence has been uploaded to the Worldwide Depository of Genomes. It can be identified by your unique GenomeID, which you are free to distribute to potential employers, insurers or acquaintances, at your discretion.

I caught my breath and took a gulp of coffee. I had been waiting for this since 545 launched its service two years ago. My grandmother, a geneticist by training, was as excited as I was about reading my future.

I opened the Annotation file.

Personality and Aptitudes

I sought out the details I needed.

Estimated IQ: 138.

Critical and Analytical

Ability: Ninety-eighth percentile

Next term's university application form did not yet have a space for GenomeID. However, it would not hurt to drop it into my Personal Statement to illustrate my curiosity about genetics. I knew that Imperial College London would have no qualms about checking my academic potential in the Depository. They would not be disappointed.

I ordered a muffin and skipped through to 'Metabolic Diseases.' Unsurprisingly, a set of seven SNPs inferred a haplotype strongly associated with type 2 diabetes. With three of my grandparents, together with the obese half of the population, now falling into that category, the emerging consensus among endocrinologists was that the condition represented the wild-type genotype of the twentyfirst century. I pinched my waistline. The muffin lost its appeal.

Appearance: Homozygosity for the BN4 allele, associated with poorly regulated cartilage formation in the nasal region.

Advertisements for rhinoplasty scrolled across the bottom of the screen. Idly, I clicked on one, wondering whether surgery would have time to heal before university started. If you cannot change nature, nurture would be on hand to help out.

'Oncogenes and Late Onset Disorders' did not surprise me in reporting homozygosity for a particular variant in $B R C A 2$. My grandmother had been one of the last patients to be treated surgically, a decade ago. The latest treatment was injected engineered leukocytes that homed in on metabolically hyperactive tumours and restricted angiogenesis, claiming to 'starve your tumours before they consume you'. This was the technology that inspired me to apply for the 'Nanobots and Cellular Machines' course at Imperial, which was refining the method and developing more applications. I drifted into a daydream where I was head of a spin-out from Imperial Innovations, jetting to conferences with a briefcase of nanobots.

My cellphone buzzed - Dad, reminding me about our lunch date. I had been absorbed in my future for the entire morning. It did not look too bad. No Huntington's, no Alzheimer's, no severe immune defects.

No nasty genetic surprises.

I handed a five-euro note to the barista. "Keep the change," I smiled.

"What's the good news?" He raised an eyebrow flirtatiously.

"I'm not going to get struck down by an inheritable disorder anytime soon."

"Fantastic," he mused, "although everyone's got to die sometime."

The receipt he gave me had something scrawled at the bottom. I squinted as I stepped out of the coffee shop and into the sunlight. It was a telephone number. Maybe my poorly regulated nasal cartilage was not so bad.

Neither he, I nor my genome noticed the oncoming bus.

\section{Erika Cule is a recent graduate in} biochemistry from Imperial College, London. This article was the winning adult entry in the Daily Telegraph/Bayer 2008 Young Science Writers competition (www.science-writer.co.uk) and is reproduced courtesy of The Daily Telegraph. 